Chronic Obstructive Pulmonary Diseases: Journal of the COPD Foundation

\author{
Original Research
}

\title{
Increased Severity and Mortality of CAP in COPD: Results from the German Competence Network, CAPNETZ
}

Dionne C.W. Braeken, $\mathrm{MSc}^{1,2}$ Frits M.E. Franssen, MD, $\mathrm{PhD}^{1,2}$ Hartwig Schütte, MD, $\mathrm{PhD}{ }^{3,7}$ Mathias W. Pletz, MD, $\mathrm{PhD}^{4,7}$ Robert Bals, MD, $\mathrm{PhD}^{5,7}$ Peter Martus, $\mathrm{PhD}^{6}$ Gernot G.U. Rohde, MD PhD ${ }^{2,7}$ on behalf of the CAPNETZ Study Group

\begin{abstract}
Background: Mortality of community acquired pneumonia (CAP) remains high despite significant research efforts. Knowledge about comorbidities including chronic obstructive pulmonary disease (COPD) might help to improve management and ultimately, survival. The impact of COPD on CAP severity and mortality remains a point of discussion.

Objectives: Assess the prevalence and clinical characteristics of COPD in the observational German Competence Network for CAP, CAPNETZ, and to study the impact of COPD on CAP severity and mortality.

Methods: 1307 consecutive patients with CAP (57.0\% males, age 59.0 \pm 18.5 ), classified as CAP-only ( $\mathrm{n}=1043$; 78.0\%) and CAP-COPD ( $\mathrm{n}=264 ; 20.2 \%)$ were followed up for 180 days. Associations between CAP, COPD and mortality were evaluated by univariate/multivariate and Kaplan-Meier survival analyses.

Results: CAP-COPD patients were older, more often males, current/former smokers, with higher confusion-urearespiratory rate-blood pressure, (CURB) scores. Length of hospital stay, urea, glucose and leucocytes plasma levels, and arterial carbon dioxide tension $\left(\mathrm{PaCO}_{2}\right)$ were significantly increased in CAP-COPD. Thirty, 90- and 180-day mortality rates were significantly increased in CAP-COPD ( $p=0.046$, odds ratio [OR] $=2.48,95 \%$ confidence interval [CI] 1.015-6.037; $p=0.003, \mathrm{OR}=2.80,95 \%$ CI 1.430-5.468; $p=0.001, \mathrm{OR}=2.57,95 \% \mathrm{CI}$ 1.462-4.498; respectively). Intensive care unit (ICU)-admission and age, but not COPD, were identified as independent predictors of shortand long-term mortality.

Conclusion: Severity as well as mortality was significantly higher in COPD patients with CAP. To improve CAP management with the aim to decrease its still-too-high mortality, underlying comorbidities, particularly COPD, need to be assessed.
\end{abstract}

\footnotetext{
Abbreviations: body mass index, BMI; community acquired pneumonia, CAP; German Competence Network for CAP, CAPNETZ; confidence interval, CI; chronic obstructive pulmonary disease, COPD; C-reactive protein, CRP; confusion, urea, respiratory rate and blood pressure, CURB; forced expiratory volume in 1 second, FEV $_{\mathbf{1}}$; forced vital capacity, FVC; intensive care unit, ICU; Global initiative for chronic

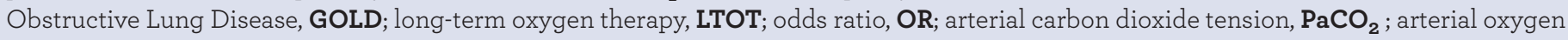
concentration, $\mathrm{PaO}_{2}$; standard deviation, $\mathrm{SD}$

Funding Support: CAPNETZ was funded by the Federal Ministry of Education and Research (BMBF), Germany (Grant No. 01KI07145). Date of Acceptance: January 26, 2014

Citation: Braeken DCW, Franssen FME, Schutte H, et al on behalf of the CAPNETZ Study Group. Increased severity and mortality of CAP in COPD: Results from the German Competence Network, CAPNETZ. J COPD F. 2015; 131-140: doi: http://dx.doi.org/10.15326/ jcopdf.2.2.2014.0149
}

This article has an online data supplement 
1 Department of Research and Education, CIRO+, Centre of Expertise for Chronic Organ Failure, Horn, the Netherlands

2 Department of Respiratory Medicine, Maastricht University Medical Centre (MUMC+), Maastricht, the Netherlands

3 Department of Internal Medicine/Infectious Diseases and Respiratory Medicine, Charité-Universitätsmedizin Berlin, Germany

4 Gastroenterology, Hepatology and Infectious Diseases, Jena University Hospital, Germany

5 Internal Medicine V - Pneumology, Medical Centre of the Saarland University, Homburg, Germany

6 Clinical Epidemiology and Applied Biostatistics, UKT Tübingen, Germany

7 CAPNETZ STIFTUNG, Hannover, Germany

\section{Address correspondence to:}

Dionne Braeken, MSc

Department of Respiratory Medicine

Maastricht University Medical Centre (MUMC+)

PO Box 5800, 6202 AZ

Maastricht, the Netherlands

dionnebraeken@ciro-horn.nl

+31 (0)433875047

\section{Keywords:}

community acquired pneumonia (CAP); chronic obstructive pulmonary disease; (COPD); mortality

\section{Introduction}

Community-acquired pneumonia (CAP) is a major cause of morbidity and mortality worldwide. ${ }^{1}$ Chronic obstructive pulmonary disease (COPD) is a common comorbidity in these patients. Older age, being male and having other comorbidities have been associated with more severe CAP in COPD patients compared with CAP in patients without COPD. ${ }^{2,3}$

Conflicting evidence exists regarding mortality rates. Some studies suggested higher mortality rates in COPD patients with $\mathrm{CAP}^{2-4}$ while others did not confirm this. ${ }^{5-8}$ The association between confusionurea-respiratory rate-blood pressure (CURB) severity scores, ${ }^{9}$ COPD and mortality, has been studied sparsely. Myint et $a^{10}$ stated that CURB scores were useful in predicting CAP mortality, but did not specify this in COPD patients. The same was reported by others, when comparing different severity scores for CAP. ${ }^{11}$ When adding age $\geq 65$ years as a component of the severity score (CURB-65), Snijders et $\mathrm{al}^{5}$ did not find any differences between CAP patients with and without
COPD in severity scoring and 30-day mortality. Crisafulli et $\mathrm{al}^{7}$ reported that CURB-65 scores were significantly higher in CAP-COPD patients, but did not investigate any possible association with mortality. A recent metaanalysis observed no significant association between COPD and increased 30-day mortality in patients with CAP. ${ }^{12}$ Less data is available on long-term mortality.

Moreover, information about clinical parameters and their association with CAP and COPD is limited, sometimes contradicting and difficult to compare. The latter may be related to the context, as some investigators described the association between clinical parameters and mortality in CAP-COPD patients, ${ }^{3,6}$ while others looked at differences in clinical parameters between CAP-COPD patients and CAP-only patients. ${ }^{7,8}$ Factors found to be associated with CAP-COPD are respiratory rate $\geq 30 / \mathrm{min}$ and increased arterial carbon dioxide tension $\left(\mathrm{PaCO}_{2}\right) .{ }^{8}$ Others, however, did not confirm this. ${ }^{7}$ Mortality in CAP-COPD was found to be related to a $\mathrm{PaCO}_{2} \geq 45 \mathrm{mmHg}^{3}$ an arterial oxygen concentration $\left(\mathrm{PaO}_{2}\right) \leq 60 \mathrm{mmHg}^{3}$ and a respiratory rate $\geq 30 / \mathrm{min}^{3,6}$

The aims of this study were to assess the prevalence of COPD in a well-characterized cohort of CAP patients, represented in the German Competence Network for CAP (CAPNETZ) and to determine clinical characteristics of these patients compared with CAPonly patients. Also, the impact of COPD on CAP severity and mortality and its determinants were prospectively studied.

\section{Materials and Methods}

Data were derived from a multi-center observational study initiated by CAPNETZ. ${ }^{13}$ Methodological details such as sampling techniques, microbiological diagnostics and laboratory processing of this study were previously published. ${ }^{14}$ The study design was approved by the local ethics committees of all participating centers. All patients gave written, informed consent.

\section{Study Population}

CAPNETZ included 1788 CAP patients between December 2009 and June 2012. Patients were eligible to be included in CAPNETZ when age was $\geq 18$ yrs, having a new pulmonary infiltrate on chest $\mathrm{x}$-ray and 1 or more clinical symptoms consisting of cough, purulent sputum, positive auscultation or fever. Patients were excluded when hospitalized during the previous 28 days, chronically immunosuppressed, HIV-infected or having active tuberculosis. Follow-up included a 
structured interview on outcome parameters at 30 and 180 days.

The presence of COPD in CAP patients was assessed from the medical record, based on post-bronchodilator forced expiratory volume in 1 second $\left(F E V_{1}\right)$ and forced vital capacity (FVC) in the previous six months. ${ }^{15}$ COPD was defined as $\mathrm{FEV}_{1} / \mathrm{FVC}$ ratio $<0.7$. $^{16}$ Study physicians assessed spirometric data, confirmed diagnosis and staged patients according to the Global initiative for chronic Obstructive Lung Disease (GOLD) guidelines. No direct spirometric data was available, only the diagnosis and staging made by study physicians. Patients were excluded from the current study when no data on COPD diagnosis was available. Moreover, cigarette smoke exposure and appraisal of inhalation medication was used in order to identify COPD patients.

\section{Study Procedures}

CURB scores were calculated based on the sum of points, with 1 point assigned for the presence of each criterion (confusion, urea $>7 \mathrm{mmol} / \mathrm{l}$, respiratory rate $\geq 30 /$ minutes, and blood pressure) on admission to the hospital. ${ }^{9,17-19}$ CURB scores were assessed instead of CURB-65 scores, as age was included as a possible confounder.

Date and cause of death was assessed from an autopsy report and/or the medical record. Cause of death was specified as pneumonia including sepsis, cardiac cause, pulmonary embolism, other, or unknown. Overall mortality and groups-specific mortality were analysed, with 30-, 90- and 180-day mortality calculated by subtracting the date of examination from the date of death. COPD severity and comorbidities were taken as additional factors possibly contributing to mortality in the CAP-COPD group. The presence of comorbid diseases was recorded from the medical records of patients.

To avoid possible misdiagnosis of undetected COPD in smoking, non-COPD patients, additional analyses were performed by excluding current and former smokers from the CAP-only group (online data supplement).

\section{Statistical Analysis}

Data analyses were performed using SPSS for Windows version 20.0. Variables were tested on normality by the Kolmogorov-Smirnov and Sapiro-Wilk test. Continuous data are presented as mean \pm standard deviation (SD) or median (interquartile range) and categorical data as counts and percentages. To compare baseline characteristics and clinical parameters of CAP-only and CAP-COPD patients, Mann Whitney U-test, Chi-square test or Fisher's Exact test were performed, as appropriate. Chi-square tests and Kaplan-Meier survival curves were assessed to analyze mortality. A Cox Model was computed, with COPD as covariate and hospitalization as strata, to analyze mortality. Odds ratio (OR) and independent predictors of mortality were assessed by logistic regression analyses. The value of $p<0.05$ was considered to be statistically significant.

\section{Results}

In total, 1788 CAP patients were included in the CAPNETZ study. Of these, 1307 CAP patients (73.1\%) matched the inclusion criteria of the current study. A total of 264 patients (20.2\%) fulfilled the diagnostic criteria for COPD.

Table 1 shows the baseline characteristics of the CAPonly and CAP-COPD patients. CAP-COPD patients were significantly older, more frequently male and had a higher mean pack years of smoking compared to CAPonly patients. The proportion of patients using longterm oxygen therapy (LTOT) was significantly increased in CAP-COPD patients. Comorbidities were more often present in CAP-COPD patients, especially chronic heart failure and other chronic respiratory/lung diseases.

Laboratory data, clinical parameters and CURB-scores are shown in Table 2. Significantly increased plasma levels of urea, glucose and leucocytes were observed in CAP-COPD patients. In addition, higher proportions of CAP-COPD patients were hypercapnic and had acidosis. $\mathrm{PaO}_{2}$ and $\mathrm{O}_{2}$ saturations were significantly lower and respiratory rates significantly higher in CAP-COPD patients, compared with CAP-only patients. CAP-COPD patients scored significantly higher on the CURB index, indicating more severe CAP.

Comparisons between CAP-COPD patients and non-smoking, CAP-only patients, (to avoid possible misdiagnosis of undetected COPD in smoking, CAPonly patients) are shown in e-Tables 1 and 2 (online data supplement). Results of baseline characteristics were comparable. Only bronchial/lung cancer was no longer significant when excluding former and current smokers of the CAP-only group. No differences in results were observed when excluding former and current smokers from the CAP-only group concerning laboratory data, clinical parameters and severity scores. 


\section{Table 1. Baseline Characteristics}

\begin{tabular}{|c|c|c|c|}
\hline & $\begin{array}{l}\text { CAP-only } \\
(n=1043)\end{array}$ & $\begin{array}{l}\text { CAP-COPD } \\
(n=264)\end{array}$ & $p$-value \\
\hline Age (years) & $57.0(41.0-72.0)$ & $71.0(63.0-77.0)$ & $<0.001$ \\
\hline \multicolumn{4}{|l|}{ Gender } \\
\hline -Male & $575(55.1)$ & $170(64.4)$ & 0.007 \\
\hline -Female & 468 (44.9) & $94(35.6)$ & \\
\hline \multicolumn{4}{|l|}{ Smoking } \\
\hline - Never smoked & $561(54.7)$ & $78(29.8)$ & $<0.001$ \\
\hline - Stopped smoking & 194 (18.9) & 104 (39.7) & \\
\hline - Smoking & $270(26.3)$ & $80(30.5)$ & \\
\hline Pack Years & $0.0(0.0-15.0)$ & $25.0(0.0-40.0)$ & $<0.001$ \\
\hline \multicolumn{4}{|l|}{ GOLD Stages } \\
\hline$-I$ & - & $55(20.8)$ & - \\
\hline - II & - & $92(34.8)$ & \\
\hline - III & - & 71 (26.9) & \\
\hline - IV & - & $46(17.4)$ & \\
\hline $\operatorname{BMI}\left(\mathrm{kg} / \mathrm{m}^{2}\right)$ & $25.4(22.2-29.4)$ & $24.8(22.4-28.9)$ & n.s. \\
\hline LTOT & $14(1.3)$ & $63(23.9)$ & $<0.001$ \\
\hline \multicolumn{4}{|l|}{ Vaccination } \\
\hline - Influenza & $268(25.8)$ & $134(51.0)$ & $<0.001$ \\
\hline - Influenza $\mathrm{A} / \mathrm{H}_{1} \mathrm{~N}_{1}$ & $53(9.7)$ & $22(15.4)$ & n.s. \\
\hline - Pneumococcal & 71 (6.9) & $63(24.0)$ & $<0.001$ \\
\hline - Pertussis & $109(11.1)$ & $11(4.3)$ & 0.001 \\
\hline \multicolumn{4}{|l|}{ Comorbidities } \\
\hline-0 & $191(37.7)$ & $41(23.0)$ & $<0.001$ \\
\hline-1 & $202(39.8)$ & $76(42.7)$ & \\
\hline-2 & $77(15.2)$ & $38(21.3)$ & \\
\hline$->2$ & $37(7.3)$ & $23(12.9)$ & \\
\hline -Chronic Heart Failure & $121(11.6)$ & $64(24.2)$ & 0.002 \\
\hline -Chronic Renal Disease & $81(7.8)$ & $26(9.8)$ & n.s. \\
\hline -Chronic Liver Disease & $23(2.2)$ & $12(4.5)$ & n.s. \\
\hline -Cerebrovascular Disease & $36(3.5)$ & $18(6.8)$ & n.s. \\
\hline -Diabetes Mellitus & $133(12.8)$ & $49(18.6)$ & n.s. \\
\hline -Chronic Respiratory/ Lung Disease & $151(14.5)$ & $74(28.0)$ & $<0.001$ \\
\hline -Asthma & $97(9.3)$ & $19(7.2)$ & $<0.001$ \\
\hline -Bronchiectasis & $9(0.9)$ & $4(1.5)$ & n.s. \\
\hline -Lung fibrosis & $9(0.9)$ & $4(1.5)$ & n.s. \\
\hline -Sarcoidosis & $2(0.2)$ & $1(0.4)$ & n.s. \\
\hline -Bronchial/Lung Cancer ${ }^{a}$ & $5(0.5)$ & $8(3.0)$ & 0.028 \\
\hline -Sleep Apnea & $12(1.2)$ & $11(4.2)$ & n.s. \\
\hline -Other & $21(2.0)$ & $31(11.7)$ & $<0.001$ \\
\hline Patient from nursing home & $17(1.6)$ & $9(3.4)$ & n.s. \\
\hline Patient hospitalized & $825(79.1)$ & $214(81.1)$ & n.s. \\
\hline Length of stay (days) & $9.0(7.0-12.0)$ & $11.0(8.8-14.0)$ & $<0.001$ \\
\hline ICU-admission & $65(7.9)$ & $19(8.9)$ & n.s. \\
\hline
\end{tabular}

Notes: Data are presented as median (interquartile range) or $\mathrm{N}(\%)$.

${ }^{a}$ Currently no radiation or chemotherapy.

CAP: community-acquired pneumonia; BMI: body mass index; LTOT: long-term oxygen therapy; ICU: intensive care unit; GOLD: Global initiative for chronic Obstructive Lung Disease; COPD: chronic obstructive pulmonary disease

\section{Mortality}

During the whole study period, 55 patients $(4.2 \%)$ died. Table 3 provides an overview of the mortality rates specified for CAP-only and CAP-COPD patients. A significant difference in 30-, 90- and 180day mortality $(p=0.046, \quad \mathrm{OR}=2.48$; $p=0.003, \mathrm{OR}=2.80 ; p=0.001, \mathrm{OR}=2.57$; respectively) was observed. Cause of death was not significantly different between CAP-only and CAP-COPD patients at the different time points. E-Table 3 (online data supplement) shows the mortality rates and cause of death of non-smoking, CAP-only patients compared with CAP-COPD patients.

In accordance with Table 3, a Kaplan-Meier survival analysis showed an increased 30-, 90- and 180-day mortality in CAP-COPD patients (Figure 1, Log Rank 11.762, $p=0.001)$. A Kaplan-Meier survival analysis of long-term mortality in non-smoking, CAP-only and CAPCOPD patients is shown in e-Figure 1 (online data supplement).

Most patients who died, were hospitalized patients. When stratified for COPD, a significant difference was found for short- and long-term mortality in hospitalized patients, compared to outpatient mortality (Table 4). The Kaplan-Meier survival analysis supports these findings (Figure 2). Moreover, a Cox Model showed a hazard ratio of 2.47 ( $p=0.001$; 95\%CI 1.432-4.251).

Table 5 shows short- and longterm mortality rates per CURB-score for both CAP-COPD and CAP-only patients. Mortality rates are low, but increase with more severe CAP according to CURB-scores.

\section{Therapy}

Therapy initiated when CAP was diagnosed, could have influenced the 


\section{Table 2. Laboratory Data, Clinical Parameters and Severity Scores}

\begin{tabular}{|c|c|c|c|}
\hline & $\begin{array}{l}\text { CAP-only } \\
(n=1043)\end{array}$ & $\begin{array}{l}\text { CAP-COPD } \\
\quad(n=264)\end{array}$ & $p$-value \\
\hline Urea (mg/dl) & $13.6(10.2-19.3)$ & $16.9(11.9-25.0)$ & $<0.001$ \\
\hline CRP (mg/dl) & $100.0(27.8-200.0)$ & $116.0(22.0-208.9)$ & n.s. \\
\hline Glucose (mg/dl) & $112.0(95.0-136.0)$ & $124.0(102.0-153.9)$ & $<0.001$ \\
\hline Leucocytes $\left(\mathrm{x} 10^{9} / \mathrm{l}\right)$ & $10.7(7.8-14.8)$ & $12.3(9.5-16.3)$ & $<0.001$ \\
\hline $\mathrm{PaO}_{2}(\mathrm{mmHg})$ & $65.0(57.0-76.0)$ & $61.0(55.0-70.0)$ & 0.001 \\
\hline $\mathrm{PaCO}_{2}(\mathrm{mmHg})$ & $34.0(31.0-38.0)$ & $37.0(33.0-43.0)$ & $<0.001$ \\
\hline$-\leq 45 \mathrm{mmHg}$ & $619(94.5)$ & $153(78.5)$ & $<0.001$ \\
\hline - > $45 \mathrm{mmHg}$ & $36(5.5)$ & $42(21.5)$ & \\
\hline $\mathrm{pH}$ & $7.5(7.4-7.5)$ & $7.4(7.4-7.5)$ & $<0.001$ \\
\hline$-\leq 7.35$ & $12(1.8)$ & $16(8.2)$ & $<0.001$ \\
\hline$->7.35$ & $645(98.2)$ & $179(91.8)$ & \\
\hline $\mathrm{O}_{2}$ saturation $(\%)$ & $94.0(92.0-96.0)$ & $92.0(89.3-95.0)$ & $<0.001$ \\
\hline Respiratory Rate & $20.0(18.0-24.0)$ & $21.0(18.0-25.0)$ & $<0.001$ \\
\hline$-\geq 30 / \mathrm{min}$ & $56(5.6)$ & $27(10.3)$ & 0.007 \\
\hline \multicolumn{4}{|l|}{ CURB } \\
\hline 0. & $548(57.3)$ & $114(44.7)$ & $<0.001$ \\
\hline 1. & $320(33.4)$ & $89(34.9)$ & \\
\hline 2. & $83(8.7)$ & $48(18.8)$ & \\
\hline 3. & $6(0.6)$ & $3(1.2)$ & \\
\hline 4. & - & $1(0.4)$ & \\
\hline
\end{tabular}

Notes: Data are presented as median (interquartile range) or $\mathrm{N}(\%)$. CRP: C-reactive protein; CURB: confusion, urea, respiratory rate, and blood pressure.
(e-Table 6, online data supplement). In CAP-only patients, deceased patients were more often treated with penicillin mono-therapy, while survived patients were more often treated with a combination therapy of penicillin and macrolides (e-Table 7, online data supplement). Analyzing therapeutic failure, no differences were observed in change of therapy after 14 days, comparing CAP-only with CAP-COPD patients $(32.4 \%$ versus $26.2 \%, p>0.05$ ).

\section{Predictors of mortality}

Logistic regression analyses were conducted to predict short-term mortality in CAP-patients by including age, gender, smoking status, LTOT, vaccination status, comorbidities other than COPD, ICU-admission and COPD as predictors. Test of the full model against a constant-only model was statistically significant (Goodness-of-fit: Chi-square $=0.008$, Hosmer and Lemeshow-test=0.389). Age was a significant predictor $(p=0.008, \quad O R=1.1, \quad 95 \% C I \quad 1.021-$ 1.149), as well as ICU admission $(p=0.047, \quad O R=4.2, \quad 95 \% C I \quad 1.022$ 17.669).

For long-term mortality, a logistic regression analysis was conducted by including age, gender, smoking status, LTOT, vaccination status, comorbidities other than COPD, CURB, COPD, ICU-admission, therapy outcomes. A significant difference between CAP-only and CAP-COPD patients was found for mono-therapy with macrolides, combination therapy of penicillin and macrolides, and combination therapy of penicillin and fluorchinolone (e-Table 5, online data supplement). Mono-therapy with macrolide and combination therapy of penicillin and macrolide was more often initiated in CAP-only patients, while a combination therapy of penicillin and fluorchinolone was more often initiated in CAP-COPD patients. When comparing deceased and survived COPD-patients, survived patients were more frequently treated with fluorchinolone mono-therapy change and GOLD-stage as possible predictors. Test of the full model against a constant only model was statistically significant for 90- and 180-day mortality (Goodness-of-fit: Chi-square=0.003, Hosmer and Lemeshow-test=0.828; Chi-square $=0.002$, Hosmer and Lemeshow-test=0.360; respectively). Age was a significant predictor for long-term mortality $(p=0.014$, $\mathrm{OR}=1.2$, 95\%CI 1.035-1.359; $p=0.035, \mathrm{OR}=1.1,95 \% \mathrm{CI}$ 1.008-1.259; respectively). Moreover, ICU-admission was predictive for long-term mortality (90-day mortality $p=0.008, O R=16.0,95 \% C I \quad 2.087-121.878 ; 180$-day mortality $p=0.018, \mathrm{OR}=9.6,95 \%$ CI $1.483-62.797$ ). 


\section{Table 3. Mortality Rates and Cause of Death}

\begin{tabular}{|c|c|c|c|c|c|}
\hline & $\begin{array}{c}\text { TOTAL } \\
(n=1307)\end{array}$ & $\begin{array}{l}\text { CAP-only } \\
(n=1043)\end{array}$ & $\begin{array}{c}\text { CAP-COPD } \\
(n=264)\end{array}$ & $p$-value & OR $(95 \% \mathrm{Cl})$ \\
\hline $\mathrm{t}=30$ days & $21(1.6)$ & $13(1.2)$ & $8(3.0)$ & 0.046 & $2.48(1.015-6.037)$ \\
\hline - Cardiac & & $1(7.7)$ & $1(12.5)$ & n.s. & \\
\hline - Pneumonia (incl. sepsis) & & $7(53.8)$ & $3(37.5)$ & & \\
\hline - Other & & $2(15.4)$ & $3(37.5)$ & & \\
\hline - Unknown & & $3(23.1)$ & $1(12.5)$ & & \\
\hline $\mathrm{t}=90$ days & $37(2.8)$ & $22(2.1)$ & $15(5.7)$ & 0.003 & $2.80(1.430-5.468)$ \\
\hline - Cardiac & & $3(13.6)$ & $1(6.7)$ & n.s. & \\
\hline - Pneumonia (incl. sepsis) & & $7(31.8)$ & $4(26.7)$ & & \\
\hline - Other & & $8(36.4)$ & $7(46.7)$ & & \\
\hline - Unknown & & $4(18.2)$ & $3(20.0)$ & & \\
\hline $\mathrm{t}=180$ days & $55(4.2)$ & $34(3.3)$ & $21(8.0)$ & 0.001 & $2.57(1.462-4.498)$ \\
\hline - Cardiac & & $5(14.7)$ & $1(4.8)$ & n.s. & \\
\hline - Pneumonia (incl. sepsis) & & $11(32.4)$ & $8(38.1)$ & & \\
\hline - Other & & $12(35.3)$ & $8(38.1)$ & & \\
\hline - Unknown & & $6(17.6)$ & $4(19.0)$ & & \\
\hline
\end{tabular}

Notes: Data are presented as $\mathrm{N}(\%)$.

OR: odds ratio; CI: confidence interval.

\section{Figure 1. CAP Patients With and Without COPD}

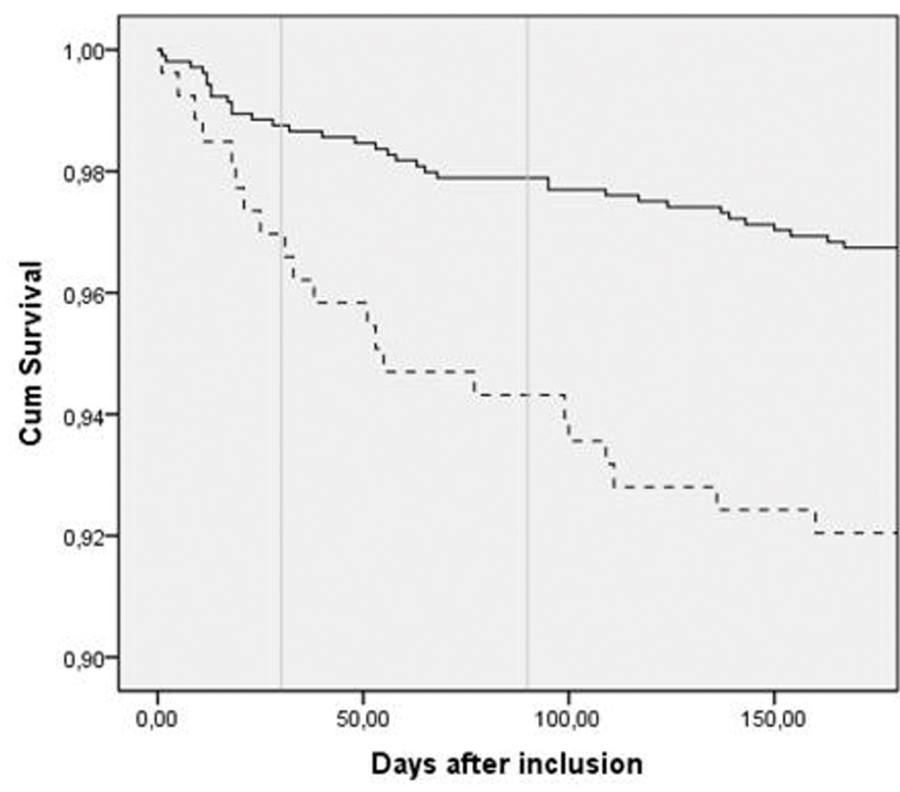

Kaplan Meier survival curve ( $t=180$ days) for CAP patients with the presence of COPD (- - -; n=264) and without (-, n=1043) the presence of COPD.
When excluding current and former smokers from the CAP-only group, results of logistic regression analysis were nearly comparable (e-Table 8 , online data supplement).

\section{Discussion}

The present multi-center prospective study has several important findings. COPD is a common comorbidity of CAP and associated with increased short- and longterm mortality. Age and ICU-admission, and not COPD per se, were independent risk factors for CAP mortality. Additionally, CAP in COPD patients is related to increased severity of pneumonia and prolonged hospitalization. The clinical presentation of CAP in COPD patients is different as compared to CAP-only patients.

In accordance with previous CAPNETZ publications, ${ }^{20,21}$ overall CAP mortality rates were low in the present population. There are several explanations for this observation. First, it should be noted that the average age of the study population was lower than in most registry studies, which partly explains the lower mortality rates. Moreover, signed informed consent was obligatory for participation in CAPNETZ, while in 


\section{Table 4. Mortality Stratified for Hospitalization and COPD}

\begin{tabular}{|c|c|c|c|c|c|}
\hline & $\begin{array}{l}\text { Out } \\
\text { CAP-only } \\
(n=214)\end{array}$ & $\begin{array}{l}\text { tient } \\
\text { AP-COPD } \\
(n=49)\end{array}$ & $\begin{array}{r}\text { Hosp } \\
\text { CAP-only } \\
(n=825)\end{array}$ & $\begin{array}{l}\text { alized } \\
\text { CAP-COPD } \\
(n=214)\end{array}$ & $p$-value \\
\hline$t=30$ days & - & - & $13(1.6)$ & $8(3.7)$ & 0.015 \\
\hline $\mathrm{t}=90$ days & $1(0.5)$ & $1(2.0)$ & $21(2.5)$ & $14(6.5)$ & 0.002 \\
\hline$t=180$ days & $1(0.5)$ & $2(4.1)$ & $33(4.0)$ & $19(8.9)$ & $<0.001$ \\
\hline
\end{tabular}

Notes: Data are presented as mean \pm SD or N (\%).

\section{Figure 2. Outpatient and Hospitalized CAP Patients With and Without COPD}

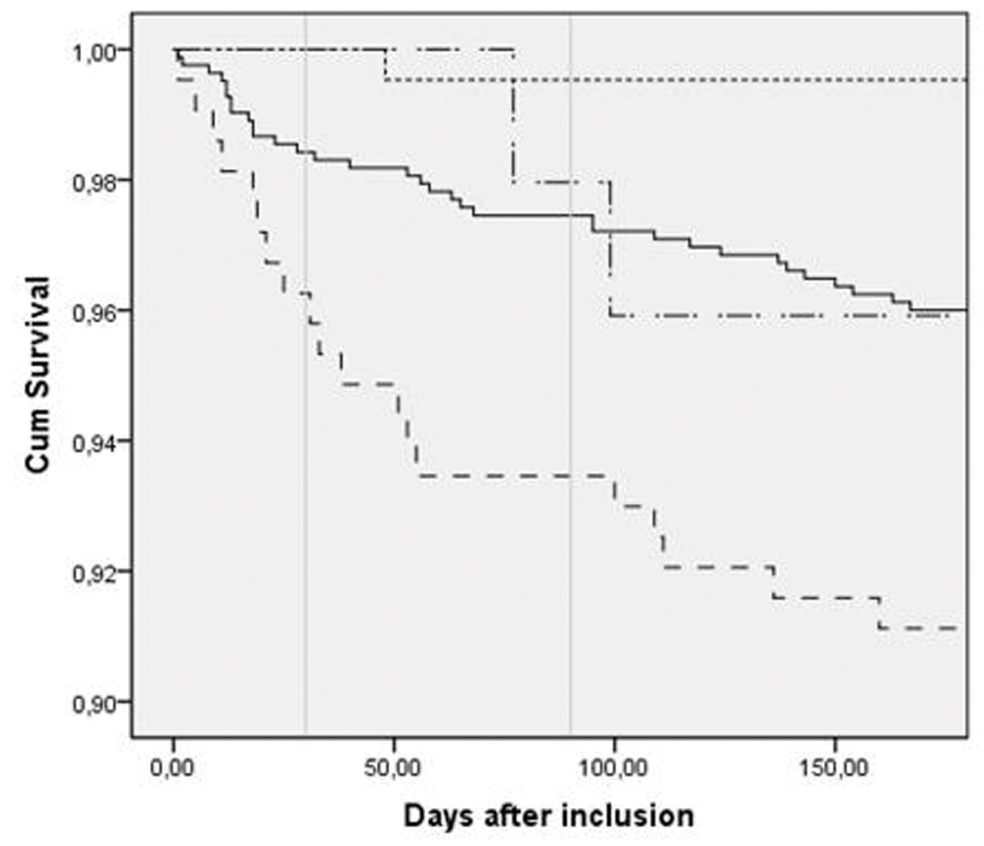

Kaplan Meier survival curve ( $\mathrm{t}=180$ days) for outpatient CAP patients without COPD $(\cdots \cdots ; n=214)$, hospitalized CAP patients without COPD ( - n=825),

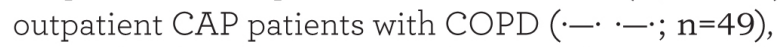
hospitalized CAP patients with COPD (- - ; $\mathrm{n}=214)$ (Log Rank 19.314; $p<0.001$ ).

population-based studies, this is not the case. ${ }^{22}$ Thus, possibly less critically ill patients were included in the present study, as more critically ill patients were not able to provide written informed consent.
Despite the low mortality rates, COPD patients had more than twice as high a risk of dying due to CAP than CAPonly patients. Other authors observed no differences in short-term mortality comparing CAP-COPD patients with CAP-only. ${ }^{5-8}$ The discrepancies found can possibly be due to inclusion of ICU patients with very severe pneumonia, ${ }^{2}$ differences in severity of airflow limitation in COPD patients, variability in other patients' characteristics, such as age and comorbidities, ${ }^{3,4,6,8}$ and the initiated therapy.

To our knowledge, this is the first study prospectively addressing 180-day mortality. Others found contradicting results. Restrepo et $\mathrm{al}^{4}{ }^{4}$ found a significantly higher 90-day mortality rate for CAP-COPD patients, whereas Crisafulli et al ${ }^{7}$ did not find differences in 90-day, as well as 1 -year mortality.

Finding significant differences when comparing CAP-only and CAP-COPD patients in univariate analysis, suggested that COPD could be of influence on mortality rates in CAP patients. However, when adjusting for other characteristics, COPD was no independent predictor of shortand long-term mortality. This is in line with a recent meta-analysis, in which COPD didn't affect mortality in patients with CAP (OR=1.44, 95\%CI 0.97-2.16). ${ }^{12}$ By our knowledge, Restrepo et $\mathrm{al}^{4}$ were the only ones who assessed the relationship between COPD and long-term mortality in multivariate analyses. They observed an association between COPD and 90-day mortality. It is worth noticing that, all referred studies used different characteristics to adjust for, which could have influenced the results.

Predictors of short- and long-term CAP mortality in the present study were age and ICU-admission. Age as an independent risk factor is not surprising, as older age itself is associated with increased mortality. In addition to age, ICU-admission was associated with an increased risk of both shortand long-term mortality. Comparable results of ICU-admission between CAP-COPD and CAPonly patients were observed by others. ${ }^{3,6,8}$ ICUadmission was identified as a significant predictor of CAP-mortality by others, which did not sustain 


\section{Table 5. Short- and Long-term Mortality per CURB-scores in CAP-only and CAP-COPD Patients}

\begin{tabular}{l|c|c|c|c|c|c|c|c|} 
& \multicolumn{4}{|c}{ CAP-only } & \multicolumn{4}{c}{ CAP-COPD } \\
$\begin{array}{l}\text { CURB } \\
\text {-scores }\end{array}$ & $\mathrm{n}$ & 30-day & 90 -day & 180 -day & $\mathrm{n}$ & 30 -day 90-day 180-day \\
\hline $\mathbf{0}$ & 114 & - & $2(1.8)$ & $4(3.5)$ & 548 & $3(0.5)$ & $6(1.1)$ & $10(1.8)$ \\
\hline $\mathbf{1}$ & 89 & $5(5.6)$ & $6(6.7)$ & $7(7.9)$ & 320 & $5(1.6)$ & $10(3.1)$ & $17(5.3)$ \\
\hline $\mathbf{2}$ & 48 & $1(2.1)$ & $5(10.4)$ & $8(16.7)$ & 83 & $2(2.4)$ & $3(3.6)$ & $4(4.8)$ \\
\hline $\mathbf{3}$ & 3 & $1(33.3)$ & $1(33.3)$ & $1(33.3)$ & 6 & $1(16.7)$ & $1(16.7)$ & $1(16.7)$ \\
\hline $\mathbf{4}$ & 1 & $1(100.0)$ & $1(100.0)$ & $1(100.0)$ & 0 & - & - & - \\
\hline \hline
\end{tabular}

medical reports because patients were included during the acute phase of their pneumonia. Hereby, there was no structured extensive baseline assessment of COPD severity. However, lung function results, together with cigarette smoke exposure and appraisal of inhalation medication, were used to identify COPD patients. Study physicians assessed the most recent lung function results and defined the appropriate GOLD stage. This resulted in data concerning $\mathrm{COPD}$ diagnosis and severity. We chose when adjusted for other confounders. ${ }^{3,6}$ In contrast, Restrepo et $\mathrm{al}^{4}$ observed increased ICU-admission in CAP-COPD patients, which did not result in differences in 30- and 90-day mortality rates comparing COPD and non-COPD patients who needed ICU-admission. Rello et $\mathrm{al}^{2}$ observed a higher ICU mortality in CAP-COPD patients, compared with non-COPD patients.

The length of hospital stay was increased in CAPCOPD patients. Pifarre et $\mathrm{al}^{8}$ showed comparable results in CAP-COPD patients, while others did not find this association. ${ }^{3,5,7}$ Differences can partly be explained by the criteria used to discharge patients, which differ between hospitals, the attending physician and different health care systems. However, longer hospital stays could be anticipated, ${ }^{24,25}$ as CAP-COPD patients suffered from more severe CAP.

The question arose if including former and current smokers in the CAP-only group could have influenced the outcomes, as there is a possibility that smoking, CAP-only patients are in fact CAP-COPD patients. Results of baseline characteristics, laboratory data, clinical parameters, severity scores and mortality rates were almost comparable to the results stated above (online data supplement). Overall, it could be stated that smoking status of CAP-only patients was not of influence on characteristics of group comparisons and mortality-rates.

A limitation of the present study is that the primary outcome of the initial CAPNETZ-study was not to describe mortality rates in CAP-COPD patients, although mortality in CAP patients was one of the objectives. Assessment of COPD as a comorbidity was added to the study starting in December 2009. Due to the study design, this assessment relied on this concept in order to keep the extensive database manageable with the drawback of lacking specific lung function data.

A strength of the present study is the extensive manner and accurate characterization of CAP patients systematically including chest x-ray. Using a combination of chest $\mathrm{x}$-ray and clinical symptoms to diagnose pneumonia, provides a more objective way of diagnosis, as compared to using only physical examination, clinical characteristics, or chest x-ray alone. $^{2,4}$ Moreover, CAPNETZ has a prospective design and is possibly the largest cohort on CAP worldwide. It is a multi-center study, with centers in 5 different European countries, including both in- and outpatients, which makes the results also relevant for the general population. The cohort is representative of patients with CAP in more economically developed countries. ${ }^{26}$

In conclusion, COPD is common in patients with CAP and results in increased severity of pneumonia. Moreover, age and ICU-admission are important risk factors for mortality in CAP. Further study of ICUadmission as a risk factor seems warranted. To us, there is no clear therapeutic pattern which could conclusively explain the differences in mortality discussed above. Although COPD itself was not an independent risk factor for mortality, this group is at higher risk of dying due to CAP, with generally a higher age and more severe CAP. Further research is necessary to identify specific COPD characteristics associated with mortality, which can possibly contribute to better management of CAPCOPD patients. 


\section{Acknowledgement}

CAPNETZ was funded by the Federal Ministry of Education and Research (BMBF), Germany (Grant No. 01KI07145). Members of the CAPNETZ study group not including the authors:

M. Dreher, C. Cornelissen (Aachen); W. Knüppel, I. Amari (Bad Arolsen); D. Stolz (Basel); N. Suttorp, P. Creutz (Berlin, Charité); T. Bauer, T. Weiß (Berlin); W. Pankow, A. Lies, D. Thiemig (Berlin-Neukölln); B. Hauptmeier, S. Ewig, D. Wehde, M. Suermann (Bochum); M. Prediger, G. Zernia (Cottbus); G. Höffken, M. Kolditz (Dresden), T. Welte, G. Barten, M. Abrahamczik, J. Naim, W. Kröner, T. Illig, N. Klopp (Hannover); C. von Plessen (Hillerød); C.
Kroegel (Jena); K. Dalhoff, S. Schütz, R. Hörster, (Lübeck); H. Buschmann, R. Kröning, (Paderborn); T. Schaberg, I. Hering (Rotenburg/Wümme); C. Schumann, C. KropfSanchen (Ulm); T. Illmann, M. Wallner (Ulm); and all study nurses.

\section{Declaration of Interest}

$\mathrm{RB}$ reports personal fees from the CAPNETZ foundation, during the conduct of the study. DB, GR, FF, HS, PM and MP have reported that no potential conflicts of interest exist with any companies/organizations whose products or services may be discussed in this article. 


\section{References}

1. Welte T, Köhnlein T. Global and Local Epidemiology of Community-Acquired Pneumonia: The Experience of the CAPNETZ Network. Seminars in Respiratory and Critical Care Medicine. 2009;30:127-135.

doi: http://dx.doi.org/10.1055/s-0029-1202941

2. Rello J, Rodriguez A, Torres A, et al. Implications of COPD in patients admitted to the intensive care unit by community-acquired pneumonia. Eur Resp J. 2006;27(6):1210-1216. doi: http://dx.doi.org/10.1183/09031936.06.00139305

3. Molinos L, Clemente MG, Miranda B, et al. Community-acquired pneumonia in patients with and without chronic obstructive pulmonary disease. J Infect. 2009;58(6):417-424. doi: http://dx.doi.org/10.1016/j.jinf.2009.03.003

4. Restrepo MI, Mortensen EM, Pugh JA, Anzueto A. COPD is associated with increased mortality in patients with communityacquired pneumonia. Eur Resp J. 2006;28(2):346-351. doi: http://dx.doi.org/10.1183/09031936.06.00131905

5. Snijders D, van der Eerden M, de Graaff C, Boersma W. The influence of COPD on mortality and severity scoring in community-acquired pneumonia. Respiration. 2010;79(1):46-53. doi: http://dx.doi.org/10.1159/000213757

6. Liapikou A, Polverino E, Ewig S, et al. Severity and outcomes of hospitalised community-acquired pneumonia in COPD patients. Eur Respir J. 2012;39(4):855-861. doi: http://dx.doi.org/10.1183/09031936.00067111

7. Crisafulli E, Menéndez R, Huerta A, et al. Sytemic inflammatory pattern of community-acquired pneumonia (CAP) patients with and without chronic obstructive pulmonary disease (COPD). Chest. 2013; 143(4):1009-1017.

doi: http://dx.doi.org/10.1378/chest.12-1684

8. Pifarre R, Falguera M, Vicente-de-Vera C, Nogues A. Characteristics of community-acquired pneumonia in patients with chronic obstructive pulmonary disease. Respir Med. 2007;101(10):2139-2144.

doi: http://dx.doi.org/10.1016/j.rmed.2007.05.011

9. British Thoracic Society. Guidelines for the management of community acquired pneumonia in adults: update. 2009. Thorax. 2009;64 (Suppl 3):iii1-iii55.

10. British Thoracic Society, Myint PK, Kamath AV, Vowler SL, Maisey DN, Harrison BD. Severity assessment criteria recommended by the British Thoracic Society (BTS) for community-acquired pneumonia (CAP) and older patients. Should SOAR (systolic blood pressure, oxygenation, age and respiratory rate) criteria be used in older people? A compilation study of two prospective cohorts. Age Ageing. 2006;35(3):286291. doi: http://dx.doi.org/10.1093/ageing/afj081

11. Aujesky D, Auble TE, Yealy DM, et al. Prospective comparison of three validated prediction rules for prognosis in communityacquired pneumonia. Am J Med. 2005;118(4):384-392. doi: http://dx.doi.org/10.1016/j.amjmed.2005.01.006

12. Loke YK, Kwok CS, Wong JM, Sankaran P, Myint PK. Chronic obstructive pulmonary disease and mortality from pneumonia: meta-analysis. Int J Clin Pract. 2013;67(5):477-487. doi: http://dx.doi.org/10.1111/ijcp.12120

13. Welte T, Suttorp N, Marre R. CAPNETZ - Community-Acquired Pneumonia Competence Network. Infection. 2004;32(4):234-238. doi: http://dx.doi.org/10.1007/s15010-004-3107-z
14. Krüger S, Ewig S, Papassotiriou J, et al. Inflammatory parameters predict etiologic patterns but do not allow for individual prediction of etiology in patients with CAP - Results from the German competence network CAPNETZ. Respir Res. 2009;10(1): 1-10. doi: http://dx.doi.org/10.1186/1465-9921-10-65

15. Global initiative for chronic Obstructive Lung Disease. Global strategy for the diagnosis, management, and prevention of chronic obstructive pulmonary disease. GOLD web site. http:// www.goldcopd.org/uploads/users/files/GOLD_Report_2013_ Feb20.pdf. Published April 2013. Accessed Feb 27, 2015.

16. Vestbo J, Hurd SS, Agusti AG, et al. Global strategy for the diagnosis, management, and prevention of chronic obstructive pulmonary disease. Am J Respir Crit Care Med. 2013;187 (4):347-365. doi: http://dx.doi.org/10.1164/rccm.201204-0596PP

17. Welte T. Risk factors and severity scores in hospitalized patients with community-acquired pneumonia: prediction of severity and mortality. Eur J Clin Microbiol Infect Dis. 2012;31 (1):33-47. doi: http://dx.doi.org/10.1007/s10096-011-1272-4

18. Bauer TT, Ewig S, Marre R, Suttorp N, Welte T, Group CS. CRB65 predicts death from community-acquired pneumonia. $J$ InternMed. 2006;260(1):93-101. doi: http://dx.doi.org/10.1111/ j.1365-2796.2006.01657.x

19. Ewig S, de Roux A, Bauer T, et al. Validation of predictive rules and indices of severity for community acquired pneumonia. Thorax. 2004;59(5):421-427. doi: http://dx.doi.org/10.1136/thx.2003.008110

20. Kothe H, Bauer T, Marre R, et al. Outcome of communityacquired pneumonia: influence of age, residence status and antimicrobial treatment. Eur Respir J. 2008;32(1):139-146. doi: http://dx.doi.org/10.1183/09031936.00092507

21. Kruger S, Ewig S, Papassotiriou J, et al. Inflammatory parameters predict etiologic patterns but do not allow for individual prediction of etiology in patients with CAP: results from the German competence network CAPNETZ. Respir Res. 2009;10:65. doi: http://dx.doi.org/10.1186/1465-9921-10-65

22. Lim WS, Rodrigo C. British Thoracic Society: Adult Community Acquired Pneumonia Audit 2012/13. British Thoracic Society website.

23. Thiem U, Niklaus D, Sehlhoff B, et al. C-reactive protein, severity of pneumonia and mortality in elderly, hospitalised patients with community-acquired pneumonia. Age Ageing. 2009;38(6):693697. doi: http://dx.doi.org/10.1093/ageing/afp164

24. Guo Q, Li H, Zhou Y, et al. Weight of the CURB-65 criteria for community-acquired pneumonia in a very low-mortality-rate setting. Intern Med J. 2012;51(18):2521-2527. doi: http://dx.doi.org/10.2169/internalmedicine.51.8159

25. Yandiola PPE, Capelastegui A, Quintana J, et al. Prospective comparison of severity scores for predicting clinically relevant outcomes for patients hospitalized with community-acquired pneumonia. Chest. 2009;135 (6):1572-1579. doi: http://dx.doi.org/10.1378/chest.08-2179

26. Lepper PM, Ott S, Nuesch E, et al. Serum glucose levels for predicting death in patients admitted to hospital for community acquired pneumonia: prospective cohort study. BMJ. 2012;344:e3397. doi: http://dx.doi.org/10.1136/bmj.e3397 